Richards, B.S. ; Schäfer, A.I. (2002) Design considerations for a solar-powered desalination system for remote communities in Australia, Desalination 144, 193-199.

\title{
Design considerations for a solar-powered desalination system for remote communities in Australia
}

Bryce S. Richards ${ }^{\mathrm{a}}$ and Andrea I. Schäfer ${ }^{\mathrm{b} *}$

a Centre for Photovoltaic Engineering, The University of New South Wales, Sydney, NSW 2052, AUSTRALIA Tel: +61-2-9385 4381; Fax: +61-2-9385 6139; e-mail: b.richards@unsw.edu.au $b$ Centre for Water and Waste Technology, Civil and Environmental Engineering, The University of of New South Wales, Sydney, NSW 2052, AUSTRALIA,

Tel: +61-2-9385 4470; Fax: +61-2-9385 6139; e-mail: a.schaefer@unsw.edu.au

\section{Abstract}

Water in many areas of Australia is scarce and of poor quality. In some areas high levels of treatment are required either due to contamination of waters or due to high salinity. Nanofiltration (NF) and low pressure RO membranes are well recognised technologies to treat waters of qualities ranging from low salinity surface water
to high salinity seawater. In remote communities the operation of such facilities may be limited by the availability of electricity. Solar, or photovoltaic energy is the ideal source of renewable energy in Australia to overcome this problem. This paper considers the various options for a small system, designed to deliver a permeate flow of 400-1000 litres/day from brackish wells. The most suitable membrane for salt retention and very high organics retention was selected and the pump energy requirements calculated. A submerged very high organics retention was selected and the pump energy requirements calculated. A submerged
ultrafiltration (UF) membrane is used as an alternative to the traditional sand and/or pre-filter cartridges. The removal of natural organics is important where disinfection of the water is required, as chlorination of waters containing natural organics may produce potentially carcinogenic by-products.

Keywords: Ultrafiltration; Nanofiltration; Photovoltaic; Submerged membrane; Remote Community, Australia

\section{Introduction}

Good quality drinking water is often a scarce resource in many remote communities around the world. Additionally, it is not always practical or possible for national electricity grids to provide power to these remote areas. Therefore, these communities are often drinking water of substandard quality, as they do not possess the electrical power or appropriate technology to purify the water. In Australia, nearly 800 remote indigenous communities rely on groundwater as their main water source. In 1998 alone, about 350 of these communities experienced water restrictions, of which hatf were attibuted to effecting nearly 18000 people [1]

The supply of fresh surface- and groundwater in Australia is limited to the northern and eastern coastal regions, while the western, central and southern regions are arid. However, as shown in Fig. 1, there are major brackish groundwater reserves in most remote regions of the country [2], which typically salinity [3].

The Australian drinking water guidelines [4] recommend that good drinking water should contain not more than $250 \mathrm{mg} / \mathrm{L}$ of chloride, a hardness of $60-200 \mathrm{mg} / \mathrm{L}$, and have less than $500 \mathrm{mg} / \mathrm{L}$ total dissolved solids (mainly inorganic salts). The adverse health effects of drinking highly mineralised water include:

- kidney and gastric disorders [5],

- reduced consumption due to poor taste [3],

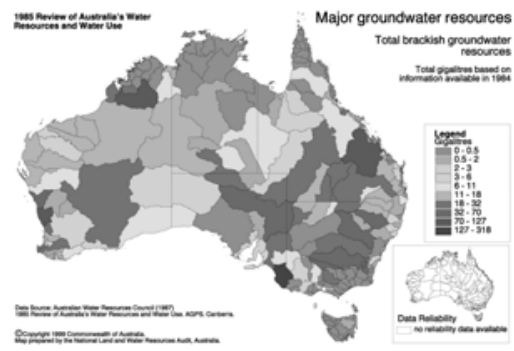

Fig. 1 Major brackish groundwater reserves that can be removed without affecting the depletion of the resource (reprinted with permission, AWRC [2]).
- and an increased sugar intake due to people adding cordial to the poor tasting water [6]. Additionally, there may be a possible link between the increased sugar levels and diabetes, which affects up to $30 \%$ of the people in some indigenous communities and can lead to premature death [5].

The design of a successful appropriate technology for indigenous community must carefully consider the following issues:

- the cultural realities and the impact of remoteness, rather than planning for urban standards,

- how highly the community values the resource,

- identifying the actual, rather than perceived, needs of the community

- the technology must be simple and robust to be able to sustain life in a remote community and a harsh environment

- the technology must be wanted by the community, and should provide water treated to the level required by the community; and

- maintenance training and education for local community members.

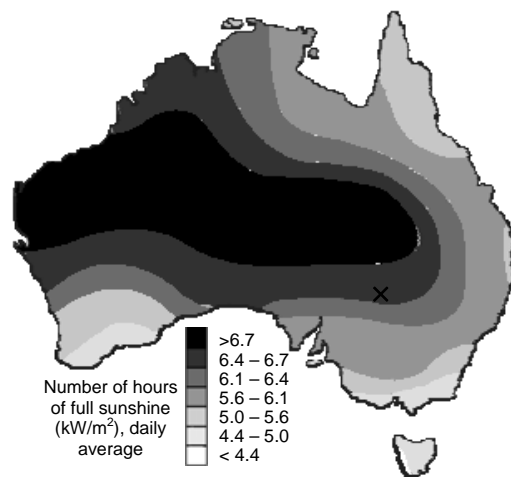

Fig. 2. Number of hours of full sunshine (daily average) received in different regions of Australia [7] (reprinted with permission, ANZSES)

from DC to AC electricity), and a tracker (to make the panels follow the path of the sun across the sky) rarely break down and require very little maintenance.

- low noise level - the only noise would be from the pump. Without batteries, the system would only run in the daytime and wouldn't disturb people at night.

- well-matched to load - solar panels produce more power in areas that receive more sunshine, where the people are likely to consume more drinking water.

Therefore, suitable groundwater reserves could be used if a suitable treatment method and renewable energy power source could be found. Luckily, most areas of Australia possess an excellent solar radiation resource, as depicted in Fig. 2, and more than two-thirds of the country receives an average of at leas 6.1 hours of full sunshine each day [7], albeit the regions with lower population density. The ' $x$ ' in Fig. 2 marks the first testing location of the system, White Cliffs, New South Wales.

Solar, or photovoltaic (PV), panels are a excellent choice for remote water treatment applications due to:

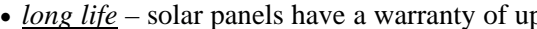
to 20 years, contain no moving parts, and withstand harsh environments.

- modularity - like membrane modules, more solar panels can be added at a later stage to meet increased demand.

- low maintenance - solar systems that do not include batteries, an inverter (to conver
- storage - it is possible to store energy in batteries, enabling a water treatment system to run on cloudy days or at night. However, batteries are expensive and cause most faults in remote area power supplies. The suggested alternative is to store treated wate suggested altenive is to store treated water before bacteria will begin to grow and cause water quality problems.

This paper considers the design parameters of a robust and simple technology for desalination using photovoltaics. The system is required to produce about $400-1000 \mathrm{~L} /$ day, typically from brackish water sources. Othe PV-powered, small RO desalination systems have been reported in the literature [3,8-11].

A schematic diagram of the system considered here is shown in Fig. 3. It should be noted that a bore pump is not included in this discussion, as the power consumption will be extremely 
dependent on the depth of the bore. In any case, solar-powered water pumping systems are a well established and reliable technology.

\section{Membrane Selection}

Pre-Treatment Step

Membrane fouling can be a limiting factor in areas where the raw water quality is poor and bacterial growth is enhanced by high temperatures. To control damage to the NF/RO membranes by biofouling, colloidal deposition and mineral scaling, pretreatment and regular cleaning are required.

A submerged ultrafiltration (UF) module, Zenon Zeeweed [17], designed for a dailyproduction of $500 \mathrm{~L}$ [12], is used as the pretreatment used in this system. The UF membrane is able to remove bacteria, cysts, viruses and other microbiological contents from the water, how are not effective for removing salts or organic matter [13]. The advantages of the submerged UF membrane include: i) the improved NF/RO feed water quality, which reduces the cleaning requirements for the NF/RO module; ii) the low pressure required to draw water through the UF membrane (up to 0.5 bar); and, iii) solids in the feed water are able to sink to the bottom of ing the need for additional pre-filters. This is a distinc improvement over the simple sand and/o cartridge filter pre-treatment steps used in other systems, which has resulted in significant biofouling and regular filter replacement has been necessary [3]

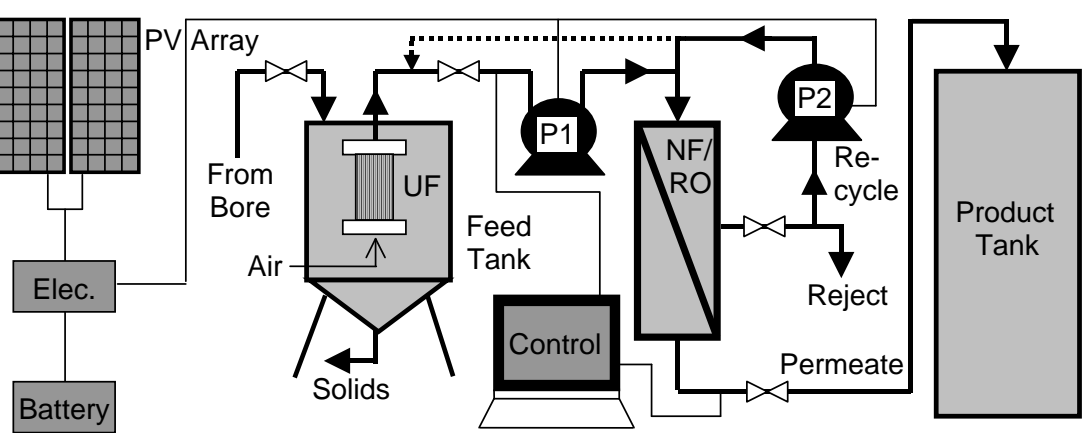

Fig. 3. Schematic diagram of the PV-powered submerged-UF/NF desalination system

\section{Desalination Membranes}

$\mathrm{RO}$ and NF are most appropriate processes if groundwater is to be treated for drinking water purposes. Although NF membranes have larger pore sizes than RO membranes and operate at a lower pressure (5-10 bar for NF vs. $10-100$ bar for RO), the majority of the salts of concern in the water may still be removed, producing excellent drinking water. The low pressure RO membrane selected for this work operates at pressures very similar to NF [14]. Due to the reduced powe requirements of NF and low pressure membranes, small renewable energy power supplies can be used to generate the required electricity $[3,12]$

The removal of contaminants, such as heavy metals, boron, fluoride and uranium using NF can be as good if not better than that of RO and NF certainly removes nitrates, which are a main source of concern [8]. Naturally occurring organics in the source water can be a nuisance if the water is to be chlointed to prevent bacterial growth, as they may form carcinogenic chlorination by-products. Both NF and RO can remove such organics, as well as many other contaminants [14]. The two membranes examined for use in this system were the Koch TFC-SR1 NF and a TFC-S low pressure RO membranes. The TFC-SR1 membrane rejects $75 \%$ of multivalent ions and $30 \%$ of monovalent ions while the TFC-S membrane retains $95 \%$ of multivalent ions and $85 \%$ of monovalent ions.

Calculations were performed in order to estimate the system's energy requirements with varying raw water salt concentration, and membrane salt retention and recovery. The calculations were based on recoveries from 10 to $95 \%$, assuming salinity consisting of $30 \%$ multivalent and $70 \%$ monovanent ions conservative assumption compared to $50 \%$ monovalen (NaCl) [8] - and a monovalent (NaCl) [8] - and a threefold concentraion increase of salinity at the membrane surface (adapted from Schäfer, p241 [14]). Concentrations in the membrane are calculated using mass balances and the pump power required is determined as the transmembrane pressure (5 bar for both membranes) plus the osmotic pressure due to the salt concentration. The calculations do not include the provision for fouling and these Additionally, the system was modelled as running in single-pass operation.

The results are plotted in Fig. 4 for a permeate production of $1000 \mathrm{~L}$. It can be seen that osmotic pressure increases with recovery, raw water salinity and membrane salt retention. The pump power requirements are also high for low recoveries, as large volumes of water

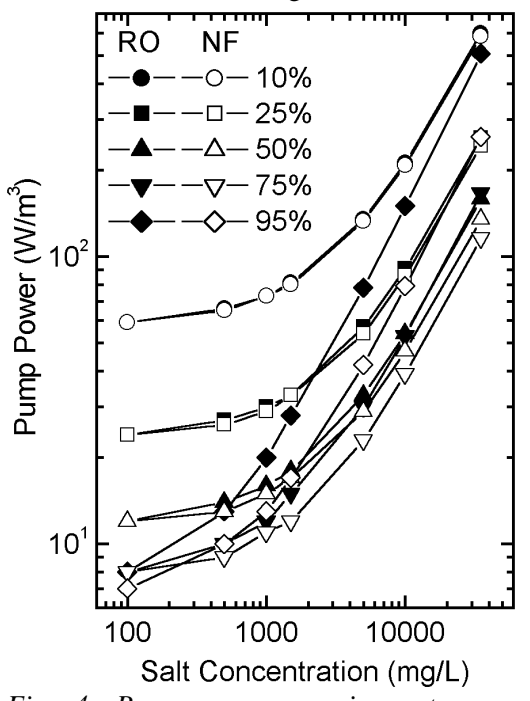

Fig. 4. Pump power requirement as a function of feed water salt concentration and recovery for the low pressure $R O$ (TFC-S; $R_{C a} 95 \%, R_{N a} 85 \%$ ) and NF membrane (TFC-SR1; $R_{C a} 75 \%, R_{N a} 30 \%$ ). have to be pumped to produce $1 \mathrm{~m}^{3}$ product water - at a recovery of $10 \%$, this is $10 \mathrm{~m}^{3}$. Although Fig. 4 indicates that the selection of the NF membrane operating at $75 \%$ recovery should result in minimum power consumption, the choice of recovery ratio should be considered futher. This will be discussed later in the section 'Energy and Water

\section{Sizing of Electrical Equipment}

High-Pressure Pump

Two $12 \mathrm{~V}_{\mathrm{DC}}$ pumps were selected for testing in the role of the high-pressure pump P1 (see Fig. 2). The first was a Shurflo 8030 diaphragm pump with a maximum operating pressure of 10.2 bar, at which the flow rate is $2.3 \mathrm{~L} / \mathrm{min}$ and the pump requires about $10 \mathrm{~A}$ of current ( 100 W of power). The second pump was a Dankoff Solor Slowpump model 1322 This is a rotary vane pump with a maximum operating pressure of about 13 bar. The Slowpump is very efficient, drawing $11.2 \mathrm{~A}$ at this pressure at an operating voltage of $15 \mathrm{~V}_{\mathrm{DC}}$ $(168 \mathrm{~W})$, while at 5 bar both pumps consume $\sim 60 \mathrm{~W}$. An additional advantage of this pump is that the flow rate remains relatively constant over a wide range of pressures, varying from $1.9 \mathrm{~L} / \mathrm{min}$ at 0.6 bar to $1.5 \mathrm{~L} / \mathrm{min}$ at $13 \mathrm{bar}$ This pump was primarily chosen for application in remote communities due to the 5-10 year replacement period for wearing parts and an expected pump life of up to 20 years.

Photovoltaic Array

The PV array for this application consisted of BP Solar BP585F laser-groove, buried-grid silicon solar cells. These cells were chosen for their high sunlight-to-electricity conversion efficiency (about 15.5\%), their excellent build quality and long expected lifetime. An important consideration is the performance reduction of crystalline silicon solar cells with increasing temperature. The performance of crystalline silicon solar cells drops by about $\sim 0.4 \%$ per ${ }^{\circ} \mathrm{C}$ [15]. Therefore, while the BP585F panels are rated at $25^{\circ} \mathrm{C}$, in the field they will actually operating at $\mathrm{T} \sim 60^{\circ} \mathrm{C}$, which results in a conversion efficiency of $\sim 13.3 \%$. This de-rating should be considered for all systems. Amorphous silicon solar panels do 
not suffer from this performance decrease, and in fact their output increases slightly at higher operating temperatures. However, the general stability of these devices is not as good.

Batteries

There are both pros and cons for including a battery or not in a small PV-powered desalination system. The disadvantages are: the short lifetime of the battery - typically 5-8 years, depending on how the battery is treated; ii) the increased maintenance of the system; iii) the battery, its control electronics and separate battery housing in the system increase the costs considerably; and, iv) losses on the order of $20 \%$ have to be reckoned with when current is directed into and out of the battery.

The advantages of having a battery in the system include, i) being able to operate the system at night (with a large battery bank), ii) system at night (with a large battery bank), ii), a single battery could act as a "buffer", presenting the high-pressure membrane with a
more constant flow to avoid fluctuations in water productivity.

Single- or Dual-Axis Tracker

The use of a 1- or 2-axis tracker (not shown in Fig. 2), which makes the PV array poin directly at the sun throughout the day, can increase the amount of water produced by up to $30 \%$. However, a tracker is a significant most likely be the least reliable component in the system. Two considerations in this are are i) the additional panels or batteries that could be purchased for the same sum of money, and ii) the remoteness of the location and the availability of (or lack thereof) loca service engineers will be a deciding factor.

Electronic Controls

For systems that include a battery, an electronic charge controller is essential. This electronic controller often incorporates additional electronics, known as a maximumpower-point tracker (MPPT), not to be confused with the trackers above. A MPPT or confused with the trackers above. A MPPT or a simpler device known as a linear curren
booster (LCB) is essential for efficien booster (LCB) is essential for efficient directly to the pump. These devices function by essentially trading voltage for current, providing more current, especially at lower light levels, to the pump. An MPPT or LCB will result in an increase in water production of about $25-30 \%$ over a directly connected PV-pump system. Two LCB's are bein tested with this system, one manufactured by Po Dankoff Solar and a cheaper alternative

\section{Energy and Water Recovery}

The use of renewable energy sources and the scarcity of water have prompted two further design considerations. Firstly, 'wate recovery' is important for applications where the recharge rate of the bore water level is slow and the resource must be carefully managed. If raw water salinity and recovery are low, then the reject stream can most likely be used for washing, cleaning and toile flushing. However, as either of these values increase, this 'concentrate' is less and less usable and requires treatment prior to disposal. This can be a severe constraint to membrane applications in any community. Therefore, as shown in Fig. 3, the option exists to recycle this water back through the NF/RO module.

This will be a feature of the unit currently under design, with a $10 \%$ single pass flow under design, with a $10 \%$ single pass flow
resulting in nearly $90 \%$ being recycled back through the membrane. The recycle stream can be fed back into the system before the high-pressure pump P1. This configuration would require a larger pump P1 to handle the increased flows, which would consume more energy. However, as there is approximaty a 0.5 bar pressure drop across the 0.5 bar pressure drop across the membrane, the 0.5 bar and then the recycle stream can be fed back into the system after pump P1. While this may require the use of a second positive displacement pump, P2, to achieve a sligh gain in differential pressure, the powe requirements of having a second pump P2 in the system may be lower than using a larger pump P1.

Related to water recovery is the concept of 'energy recovery', commonly used in large RO desalination plants. Typically, this involves recovering the energy in the recycle and/or reject stream by passing it through turbine or reverse operated centrifugal pump [18]. This form of energy recovery is know to work well for large, high-pressure (>60 bar) systems, however the amount of powe generated in our case would be small.

An alternative is to fix the Pelton turbine (or impeller pump) onto the same shaft as the motor for pump P1 and recover the useful work in this manner. There are still two energy conversion steps - from hydraulic to mechanical, and back to hydraulic again which limits the efficiency. For example, even if the pump and turbine were both $75 \%$ efficient, the 'work recovery' step would only be just over $50 \%$ efficient. There have been more recent developments in the area of 'pressure exchangers' (PE), where there are no energy conversion stages and the efficiency of these technologies is $>95 \%$. However, again PE would seem to be most efficient for larger high-pressure RO plants. Another possibility is a method implemented originally by Keefer $e$ al. [16], and more recently Mathew et al. [3]. In this system, the energy from the reject stream is recovered by injecting it behind the piston from pump P1, assisting it on its upstroke and greatly reducing the power consumption of the pump. The only drawback to this system would seem to be controlling the necessary valves, however from all the available technologies it would appear to be the most applicable to small systems.

\section{Conclusions}

The combination photovoltaic energy and membrane processes are a great technology for remote community applications. Decreasing costs and low maintenance combined with a compact and robust design make this an ideal solution. The system is modular an transportable, and no chemicals are required, thus ensuring the safety of community members. The use of a submerged UF membrane is anticipated to enhance pretreatment performance over existing systems. $\mathrm{NF}$ or low pressure $\mathrm{RO}$ membranes, providing suitable rejection at an operating pressure of $\sim 5$ bar provide the opportunity for using sola power. The system described here is currently entering its first trial in a remote region.

\section{References}

[1] Australian Bureau of Statistics (1999), Housing and Infrastructure in Aboriginal and Torres Strait Islander Communities, Canberra.

[2] Australian Water Resource Council (AWRC) (1987), 1985 Review of Australia's Water Resources and Water Use, Canberra.

[3] K. Mathew, S. Dallas, G. Ho and M. Anda, Commercialisation of an Innovative SolarPowered Village Potable Water Supply, Austrlian and New Zealand Solar Energy Society
Conference (1999), Geelong, Victoria.

[4] National Health and Medical Research Council (NHMRC) (1996), Australian Drinking Water Guidelines, Canberra.

[5] NHMRC (1996), Promoting the Health of Aboriginal and Torres Strait Island Communities, Canberra.

[6] Healthabitat (1999), The National Indigenous Housing Design Guide, Commonwealth Department of Family and Community Services.

7] T. Lee, D. Oppenheim and T. Williamson, Australian Solar Data Radiation Handbook (ASDRH), Energy Resource Development Australian and New Zealand Solar Energy Society (ANZSES).

[8] D.G. Harrisson, G.E. Ho and K. Mathew Desalination using Renewable Energy in Australia Renewable Energy, 8 (1 - 4) (1996), 509-513.

[9] B.G. Keefer, R.D. Hembree and F.C. Schrack, Optimized matching of solar photovoltaic powe with reverse osmosis desalination, Desalination 54 (1985), 89-103.

[10] A. Joyce, D. Loureiro, C. Rodrigues and S. Castro, Small reverse osmosis units using PV systems for water purification
(2001), 39-44. [11] D. Herold, V. Horstmann, A. Neskakis, J. Plettner-
Marliani, G. Piernavieja and R. Calero, Small scale photovoltaic desalination for rural water supply demonstration plant in Gran Canaria, Renewable Energy 14(1-4) (1998), 293-298.

[12] W.T. Johnson, Recent advances in micro-filtration for drinking water treatment, AWWA Annual Meeting, 1999, Chicago.

13] J.A. Redondo, Brackish-, sea- and wastewate desalination, Desalination 138 (2001), 29-40.

[14] A.I. Schäfer, Natural Organics Removal Using Membranes: Principles, Perfo

[15] M.A. Green, Solar Cells: Operating Principles, Technology and System Applications, Univ. of New South Wales, Sydney, Australia, 1986.
Nectolic

[16] Alternative Technology Associtation, http://www.ata.org.au

[17] P. Côté, J. Cadera, J. Coburn, A. Munro, A new immersed membrane for prestreatment for revers osmosis, Desalination 139 (2001) 229-236.

[18] L. Drabløs, Aqualyng with pressure recuperation, Desalination 139
(2001) 149-153. 